\title{
Core Scale analysis on Asphaltene Flocculation Inhibition and Deposits removal by Ultrasonication
}

\author{
Mahmood Amani*, Arnel Carvero, Rommel Yrac, Amr Sayed and Ahmed Abdul Rauf \\ Petroleum Engineering Program, Texas AEM University at Qatar, P.O. Box 23874, Doha, Qatar
}

\section{Article Info}

\author{
*Corresponding author: \\ Mahmood Amani \\ Texas A\&M University at Qatar \\ P.O. Box 23874 \\ Doha, Qatar \\ Tel: +974-4423-0119 \\ E-mail: amani@tamu.edu
}

Received: September 29, 2017

Accepted: October 5, 2017

Published: October 11, 2017

Citation: Amani M, Carvero A, Yrac R, Sayed A, Rauf AA. Core Scale Analysis on Asphaltene Flocculation Inhibition and Deposits Removal by Ultrasonication. Int J Petrochem Res. 2017; 1(2): 96-100. doi: 10.18689/ijpr-1000117

Copyright: (c) 2017 The Author(s). This work is licensed under a Creative Commons Attribution 4.0 International License, which permits unrestricted use, distribution, and reproduction in any medium, provided the original work is properly cited.

Published by Madridge Publishers

\begin{abstract}
Asphaltene buildup in the near wellbore region is an increasingly problematic phenomenon, especially in mature fields. Research on ultrasonic treatment to address this issue has increased in recent years, with a field trial on mature fields exhibiting favorable characteristics. Investigation of petrophysical characteristics, precipitation of asphaltenes in rock samples, employment of ultrasonication to remove/inhibit deposits, investigation of optimum sonication time, and the resultant increase of permeability to brine and crude oil are discussed and illustrated. Prevention and or removal of asphaltene deposits inside the wellbore as well as the nearby wellbore region can significantly improve in the recovery of the petroleum reservoirs.
\end{abstract}

Keywords: Asphaltene Deposition; Ultrasonic Waves; Enhanced Oil Recovery; Core Analysis.

\section{Introduction}

Asphaltenes are large, complex and polar molecules in petroleum crudes that consist of aromatic rings with oxygen, nitrogen, or sulfur atoms. They are not soluble in crude oil, but rather suspended as colloids, which are aggregates of asphaltene stabilized in the oil by its resin-content. This is due to the fact that resins are also polar components of the oil and thus can easily be adsorbed on these colloidal particles surfaces. When this stable condition is disturbed, the asphaltenes form flocs, which are a larger group of precipitates [1]. In the field, this destabilization occurs during miscible flooding, after acid stimulation or in mature reservoirs due to the drop in pressure.

The deposition of asphaltenes around the wellbore of oil producing wells can greatly affect their productivity as asphaltenes-deposition clogs the connected pores around the well and restricts fluid flow. The severity of asphaltene-deposition depends on the composition of the crude produced, especially its asphaltene content (which can be as high as $60 \%$ ) and the resin-to-asphaltene volume ratios (at which the crude is not stable for ratios below 1:1) [2].

This deposition is classically treated with the injection of chemicals. The use of ultrasonic waves can offer a less expensive alternative to address the issue [3]. Other advantages of the use of sonication for asphaltene deposition treatment (and inhibition) includes better zonal control, to only target wanted intervals, and the ability to perform stimulation while producing, thus reducing non-productive time.

The purpose of this paper is to first describe the methodologies used to determine porosity, permeability and asphaltene deposition criteria for homogenous rock samples. The results of these are then used to create asphaltene deposition in rock samples and compare the resultant permeability to earlier results. Sonication is conducted and permeability is compared again to determine treatment effectiveness. 


\section{Methodology}

Often questions arise about the reservoir production; how and of what composition will the reservoir produce. In the oil and gas industry, reservoir and production engineers face a challenge when it comes to maximizing the recovery of hydrocarbons from the reservoir in a very short amount of time. These various questions can be answered by finding the phase and volumetric behavior of the hydrocarbons produced [4]. Porosity and permeability determination forms the basis of these calculations and crucial answers. In this research, the same building blocks are used for further testing regarding asphaltene deposition and sonication on samples.

Sample preparationof the rock-sample cores, is the key for an organized and successful experimentation. It will give initial information about the properties of the core sample and will dictate the flow of the operation. Primary testing was in regards to determining porosity and permeability of samples. Since every sample was a smaller segment (two inches in length and one inch in diameter) of a larger foot-long core sample of the same rock segment, it was expected that there will be relatively low levels of variation in permeability and porosity amongst the smaller individual core samples [7].

As part of obtaining initial information about the core sample, a porosity test is necessary. The samples tested were in the same magnitude/range of porosity as highlighted above. This testing was conducted using a brine saturation setup that is described further in the section detailing the procedure used to determine permeability. Calculating the porosity of the core sample leads to information that is required to proceed with further testing of permeability, especially with regards to asphaltene deposition [8]. This is of increased significance since lower porosity implieshigher fluid inlet pressure. High inlet pressure permeability can be time consuming and hazardous.

It is the sole purpose of the project to see the impact of applying ultrasonic waves on a sample, which has asphaltene deposition. One of the method that was used to serve the purpose was by testing the permeability of the sample. Core sample after having been flooded with heptane and crude oil was tested before and after subjecting the sample into an ultrasonication for a predetermined time with permeability to evaluate the effect of the treatment used.

\section{Procedure}

\section{Sample Preparation}

a. Indiana Limestone samples that were obtained at 1 -foot in diameter were cut intocore samples 2 inches in length.

b. Samples were weighed, cleaned and sequentially arranged in order to remain within homogenous limits of the original limestone sample.

\section{Porosity Determination}

c. Core samples were dried in an oven at 80 degrees Celsius overnight. d. After the drying process, the sampleswere re-weighed as W1.

e. The weighed samples were then stored in a cell under vacuum.

f. After 8 hours under vacuum, the cores were then saturated with $2 \%$ solids by weight brine solution overnight, in a setup demonstrated in Figure 1.

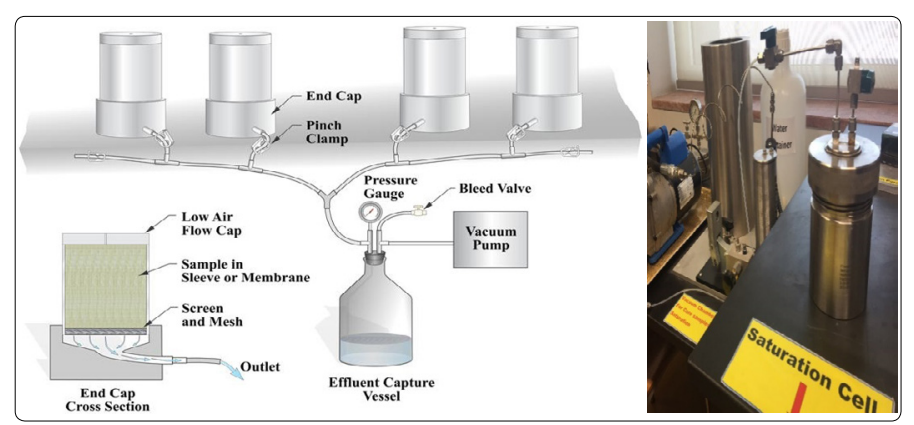

Figure 1. Brine Saturation Setup

g. At the end of the saturation cycle, the cores were harvested and re-weighed as W2.

h. Porosity was then calculated using:

$\%$ Porosity $=((\mathrm{W} 2-\mathrm{W} 1) / \mathrm{W} 2) * 100$

i. Initial Porosity results are shown in Table 1.

\begin{tabular}{|c|c|c|c|c|c|}
\hline \multirow{2}{*}{ Sample } & Diameter & Length & \multicolumn{2}{|c|}{ Weight, grams } & Porosity \\
\cline { 2 - 6 } & $\mathbf{c m}$ & $\mathbf{c m}$ & Initial & Final & \% \\
\hline A & 2.511 & 4.899 & 51.825 & 56.464 & 8.216 \\
\hline B & 2.511 & 4.918 & 52.014 & 56.690 & 8.248 \\
\hline C & 2.510 & 5.074 & 53.818 & 58.651 & 8.240 \\
\hline D & 2.510 & 5.069 & 53.718 & 58.471 & 8.129 \\
\hline A1 & 2.545 & 4.876 & 51.923 & 56.670 & 8.377 \\
\hline B1 & 2.521 & 4.820 & 51.502 & 56.252 & 8.444 \\
\hline C1 & 2.511 & 4.906 & 52.018 & 56.661 & 8.194 \\
\hline D1 & 2.524 & 5.044 & 53.865 & 58.695 & 8.229 \\
\hline
\end{tabular}

Table 1. Core Dimensions and Initial Porosity Results

\section{Permeability Determination}

j. Core samples of 1 inch in diameter and 2 inches in length, which were previously saturated with $2 \%$ brine solution was placed inside the core holder of the Pore-Core scale flooding setup illustrated and shown in Figure 2.

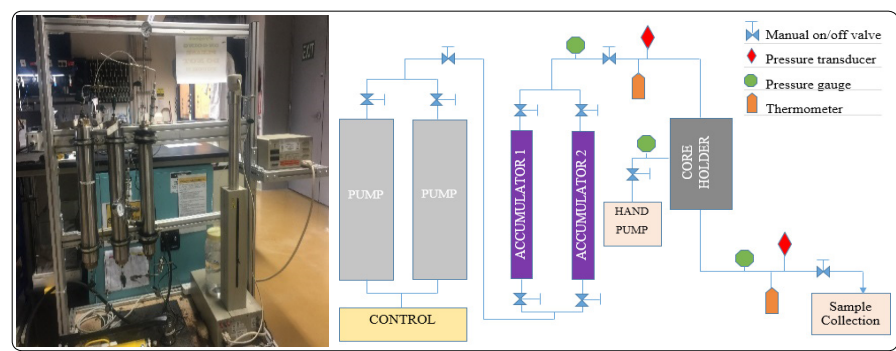

Figure 2. Pore-Core Scale Flooding Actual Setup

k. The cores were then flooded with $2 \%$ solids by weight brine solution to get the permeability to brine of the samples. Pressure inlet and pressure outlet values were monitored using a commercially available software apparatus demonstrated in Figure 3. 


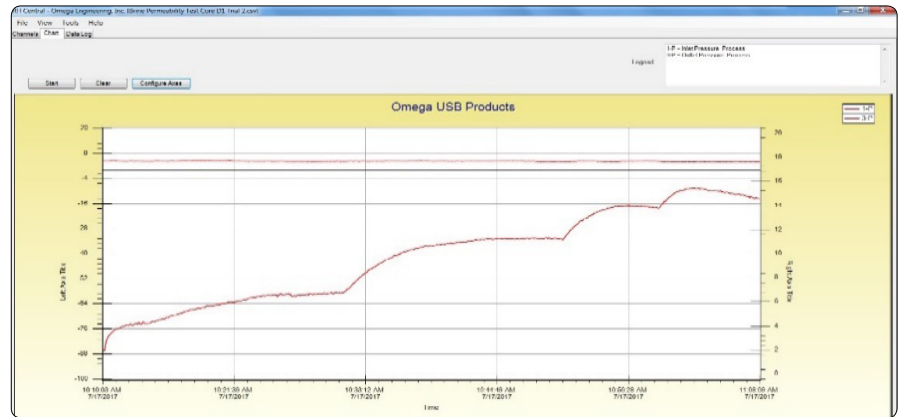

Figure 3. Permeability Monitoring and Measuring Software

\section{Asphaltene Deposition}

1. The cores were then flooded with Heptane and crude oil to develop asphaltene deposition in the core samples.

2. After setting the core samples overnight inside the core holder, permeability determination using crude oil was done on the core samples before sonication as an initial permeability value before sonication.

\section{Sonication}

a. The core samples were then taken out of the core holder to be subjected to sonication. Four samples from each relatively homogenous set wereselectedto undergo different sonication durations, which were 2.5, 5, 7.5 and 10 minutes. Sonication time was up to 10 minutes and at $90 \%$ of maximum amplitude (with 1.8 sonotrod booster) to protect the ultrasonic machine from overheating and ultimately being damaged.

b. After the sonic ation, the core samples werethen replaced inside the core holder for post-sonication permeability testing with crude oil as final, treated permeabilities.

\section{Results and Discussion}

To provide some background and to understand where the obtained results fall in the grand scheme of oil production, the following discussion is presented. In a reservoir, there are various properties that affect how we can successfully produce hydrocarbons from the formation. Some properties, including temperature, pressure, and volume, differ in every reservoir. Knowing these properties helps us understand how our fluid will go ahead and flow through the reservoir and it helps us "evaluate reserves and to develop the optimum recovery plan" [3].

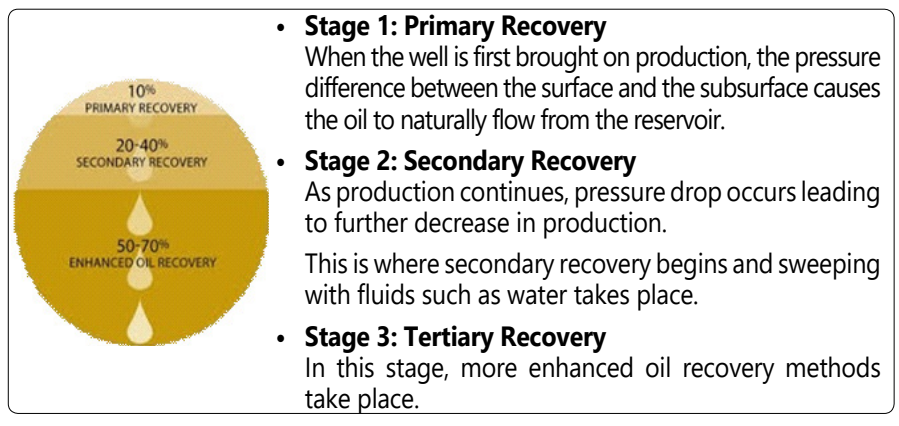

Figure 4. Three Stages of Oil Recovery
Through this experimental set-up, tertiary recovery was the ultimate objective. The tertiary, also known as enhanced oil recovery promotes different kind of processes wherein 50$70 \%$ of the remaining oil in place can be recovered. Preventing asphaltene deposition in the tubing and the near wellbore region can be very helpful in obtaining this additional recovery. Recent research has demonstrated that ultrasonic technology has been emerging as a remarkable option based on its effectiveness and ease of employment [5].

The results of permeability to brine before and after sonication is detailed in Table 2. No decrease or increase in permeability was observed in $\sim 40 \%$ of sonicated samples. Figure $5 \& 6$ detail initial permeability values for two sets of core samples described in the methodology section.

\begin{tabular}{|c|c|c|c|c|c|c|c|}
\hline \multirow{2}{*}{ Sample } & \multirow{2}{*}{$\begin{array}{c}\text { Exposure } \\
\text { Time }\end{array}$} & \multicolumn{7}{|c|}{ Permeability } \\
\cline { 3 - 9 } & & Brine & \multicolumn{2}{|c|}{ Before Sonication } & \multicolumn{2}{|c|}{ After Sonication } & Impact \\
\hline & minutes & $\mathrm{mD}$ & $\mathrm{mD}$ & $\%$ Plugged & $\mathrm{mD}$ & $\%$ Plugged & $\%$ \\
\hline A & 2.5 & 119.000 & 12.900 & 89.160 & 11.900 & 90.000 & -0.840 \\
\hline B & 5 & 304.600 & 11.000 & 96.389 & 10.900 & 96.422 & -0.033 \\
\hline C & $\mathbf{7 . 5}$ & $\mathbf{1 5 8 . 1 0 0}$ & $\mathbf{2 . 9 0 0}$ & $\mathbf{9 8 . 1 6 6}$ & $\mathbf{3 . 7 0 0}$ & $\mathbf{9 7 . 6 6 0}$ & $\mathbf{0 . 5 0 6}$ \\
\hline D & 10 & 117.900 & 4.800 & 95.929 & 4.900 & 95.844 & 0.085 \\
\hline A1 & 2.5 & 50.300 & 10.300 & 79.523 & 8.400 & 83.300 & -3.777 \\
\hline B1 & 5 & 64.700 & 8.400 & 87.017 & 7.800 & 87.944 & -0.927 \\
\hline C1 & $\mathbf{7 . 5}$ & $\mathbf{2 9 2 . 9 0 0}$ & $\mathbf{2 . 9 0 0}$ & $\mathbf{9 9 . 0 1 0}$ & $\mathbf{4 . 7 0 0}$ & $\mathbf{9 8 . 3 9 5}$ & $\mathbf{0 . 6 1 5}$ \\
\hline D1 & 10 & 340.000 & 3.000 & 99.118 & 3.000 & 99.118 & 0.000 \\
\hline
\end{tabular}

Table 2. Brine Permeability Before and After Sonication, and Impact Percentage

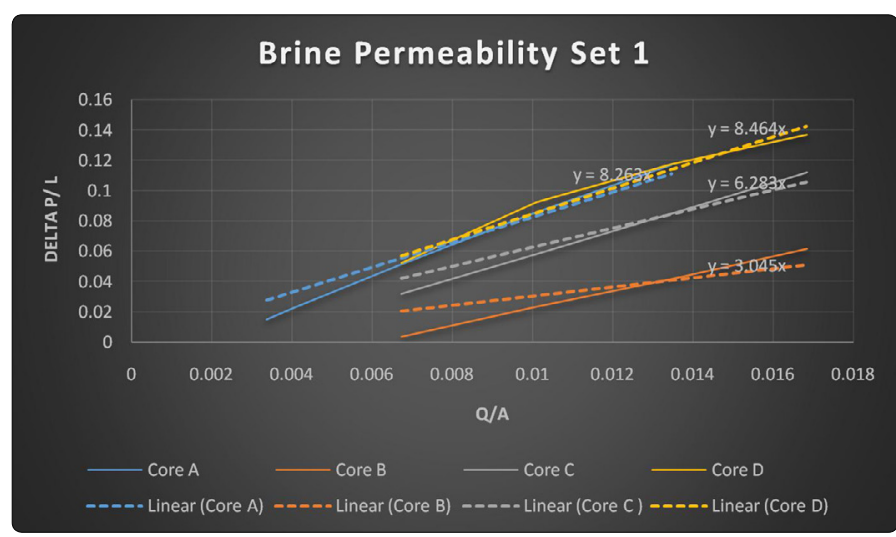

Figure 5. Initial Permeability Indication by Brine of Core Samples Set $1(A, B, C$ and $D)$

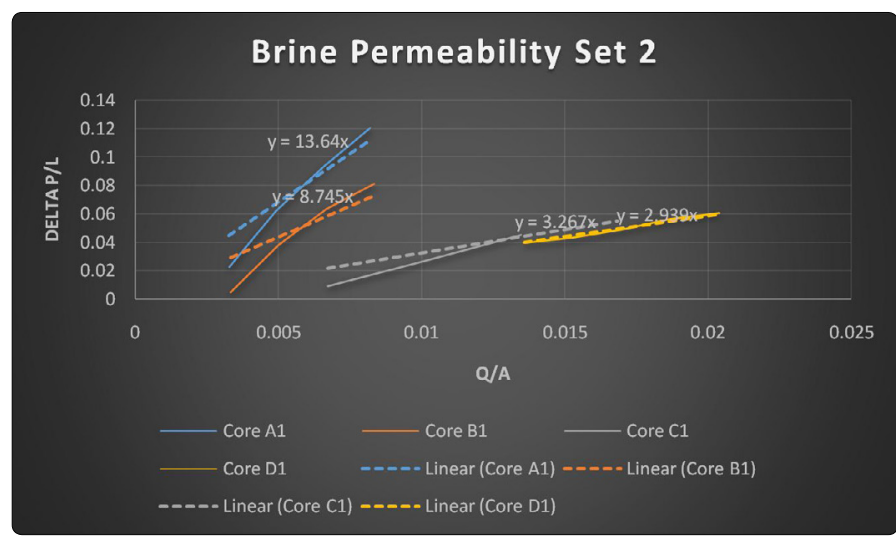

Figure 6. Initial Permeability Indication by Brine of Core Samples Set 2 (A1, B1, C1\& D1) 
The brine permeability test for the core sample serves as an initial permeability indication to be used later in calculations to gauge the impact of ultrasonic treatment of the asphaltene deposits. After obtaining results from the first set of core samples (Set 1) similar tests on a second set of core samples (Set 2) were done for verification purposes.

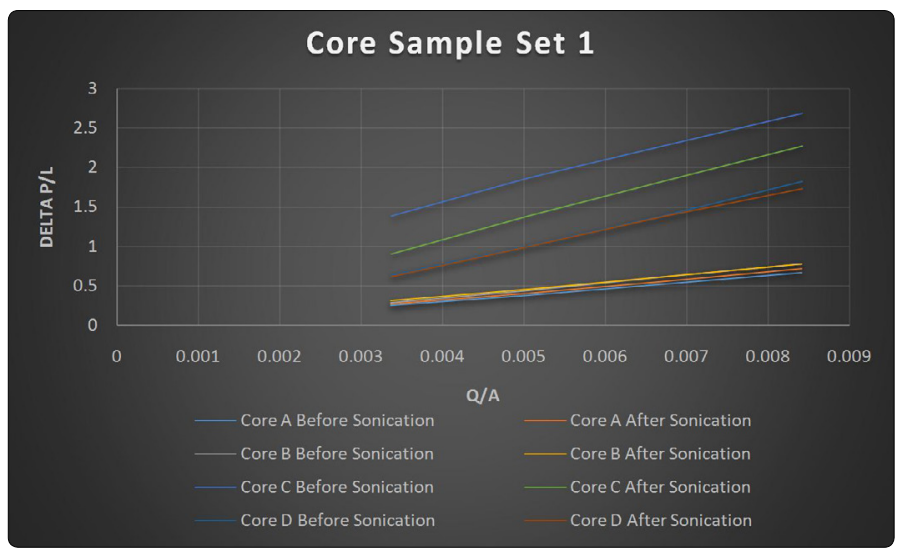

Figure 7. Secondary Permeability Results on Core Samples Set 1 ( $A$, $B, C$ and D)

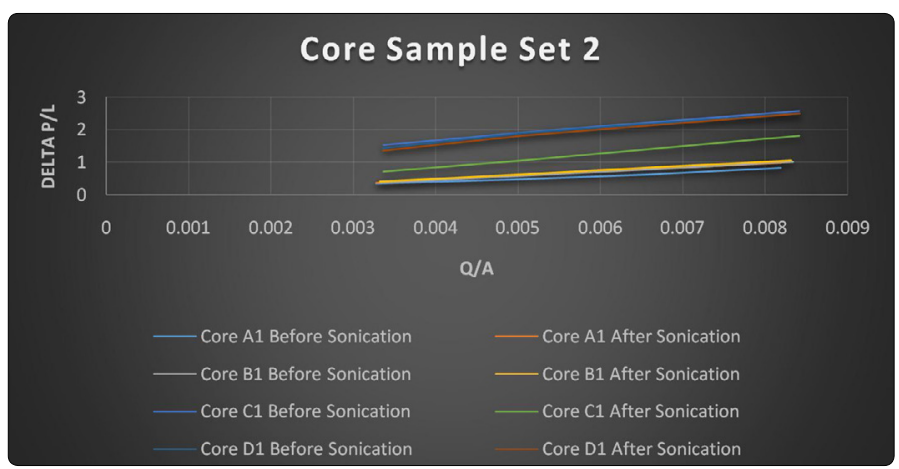

Figure 8. Secondary Permeability Results on Core Samples Set 2 (A1, B1, C1 and D1)

Figures $7 \& 8$ show the permeability curves of samples Set 1 and Set 2 with the impact caused by ultrasonic treatment on core samples with asphaltene deposition. This is the postsonication permeability and follows the same trend for both sets and pre-sonication permeability ranges. This highlights no erroneous outliers and homogeneity of the larger rock sample. Figure 9 also demonstrates the post-sonication permeability impacts for both sample sets.

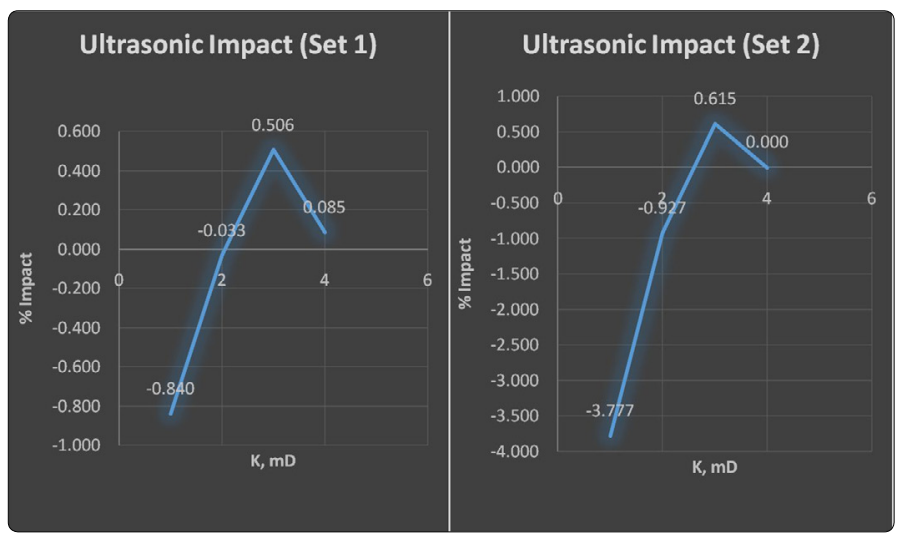

Figure 9. Post-Sonication Permeability Impacts for both Sample Sets

\section{Conclusions}

- A downhole method for ultrasonic treatment can be helpful to enhance oil recovery on failing oil wells.

- This method increases the permeability of the bottom hole zone and reduces blockages.

- This method is simple, and environmentally safe

- The effect due to ultrasonic treatment can last for few months. According to Vladimir The Author(s). This affect can last 3-12 months [6].

- It was observed that at 7.5 minutes of sonication time permeability increase was at the highest levels in relation to higher and lower exposure times for both sets of core samples, demonstrated by core samples $C$.

- A trend can be drawn from the results obtained in the post-sonicationpermeability test for both homogeneity samples (Set1 and Set 2).

- Core samples were not uniform with respect to brine permeability. The displacement of brine in the sample verified the flow assurance of liquid, monitored entirely by a commercially available software, also used for permeability investigations with crude oil.

- Core samples with low permeability are difficult to test as inlet pressures are high and time consuming. The highest rate of impact was recorded in core samples $C$ which are 0.506 and 0.615 corresponding to $27.6 \%-62 \%$ increase in oil recovered after sonication.

Combing the results of this current research with field research cited above, ultrasonication can be confirmed as a method to decrease asphaltene deposition's negative effects on rock permeability. It has also been demonstrated that an optimum treatment time for ultrasonic waves exists, and must be determined to a reasonable level of accuracy in further studies. This research should further pave the way toward further pilots and studies to lead to widespread utilization and adoption in the field.

\section{Acknowledgment}

This publication was made possible by an NPRP award [NPRP 5 - 352 - 2 - 137] from the Qatar National Research Fund (a member of The Qatar Foundation). The statements made herein are solely the responsibility of the authors.

\section{Conflict of Interest}

The authors confirm that there is no conflicts of interest regarding this manuscript.

\section{References}

1. Amani $M$, Retnanto A. AlJuhani $S$, Al-Jubouri $M$, Shehada $S$, Yrac R. Investigating the Role of Ultrasonic Wave Technology as an Asphaltene Flocculation Inhibitor, an Experimental Study. International Petroleum Technology Conference, doha, Qatar 2015. doi: 10.2523/IPTC-18473-MS 
2. Gollapudi UK, Bang SS, Islam MR. Ultrasonic Treatment for Removal of Asphaltene Deposits During Petroleum Production.In SPE Formation Damage Control Symposium, Lafayette, Louisiana, USA. Society of Petroleum Engineers. 1994. doi: 10.2118/27377-MS

3. Danes A. Developments in Petroleum Science. In PVT and Phase Behavior of Petroleum Reservoir Fluids. Els Sci. 1998; first edition Chapter. 47.

4. Freyss H, Guieze P, Varotsis N, Khakoo A, Lestelle K, Simper D. PVT Analysis for Oil Reservoirs. Reservoir Engineering. Schlumberger. 1989; 37(1): 4-15.

5. Calibration. Schlumberger Oilfield Glossary. Retrieved online. 2017.
6. Vladimir OA, Marat SM, Abramova VA, Esipov IB, Mason TJ. Ultrasonic Technology for Enhanced Oil Recovery from Failing Oil Wells and the Equipment for its Implementation. Ultrason Sonochem. 2013; 20(5): 1289-1295. doi: 10.1016/j.ultsonch.2013.03.004

7. Najafi I, Amani M. Asphaltene Flocculation Inhibition with Ultrasonic Wave Radiation: A Detailed Experimental Study of the Governing Mechanisms. Advances in Petroleum Exploration and Development. 2011; 2(2): 32-36.

8. Najafi I, Mousavi S, Ghazanfari MR, Ghotbi MHC, Ramazani A, Kharrat R, Amani M. Quantifying the Role of Ultrasonic Wave Radiation on Kinetics of Asphaltene Aggregation in a Toluene-Pentane Mixture. Petroleum Science and Technology. 2011; 29(9): 966-974. doi: 10.1080/10916460903394144 